\title{
BMJ Open Significant amelioration of hepatitis C virus infection in a hyperendemic area: longitudinal evidence from the COMPACT Study in Taiwan
}

\author{
Pei-Chien Tsai, ${ }^{1}$ Ching-I Huang, ${ }^{1,2,3}$ Ming-Lun Yeh, ${ }^{1,2,3}$ Chung-Feng Huang, ${ }^{1,2,3}$ \\ Meng-Hsuan Hsieh, 1,2,3,4 Jeng-Fu Yang, ${ }^{1,4}$ Po-Yao Hsu, ${ }^{1,3}$ Po-Cheng Liang, ${ }^{1}$ \\ Yi-Hung Lin, ${ }^{1}$ Tyng Yuan Jang, ${ }^{1,3}$ Ming-Yen Hsieh, ${ }^{1,5}$ Chia-Yen Dai, ${ }^{1,2,3}$ Zu-Yau Lin, , ${ }^{1,2}$ \\ Shinn-Chern Chen, ${ }^{1,2}$ Jee-Fu Huang (D) , 1,2,3,5,6 Ming-Lung Yu, ${ }^{1,2,3,6}$ \\ Wan-Long Chuang, ${ }^{1,2,3}$ Wen-Yu Chang ${ }^{1}$
}

To cite: Tsai P-C, Huang C-I, Yeh M-L, et al. Significant amelioration of hepatitis $\mathrm{C}$ virus infection in a hyperendemic area: Iongitudinal evidence from the COMPACT Study in Taiwan. BMJ Open 2021;11:e042861. doi:10.1136/ bmjopen-2020-042861

- Prepublication history for this paper is available online. To view these files, please visit the journal online (http://dx.doi. org/10.1136/bmjopen-2020042861).

Received 16 July 2020

Revised 20 December 2020

Accepted 09 February 2021
Check for updates

(c) Author(s) (or their employer(s)) 2021. Re-use permitted under CC BY-NC. No commercial re-use. See rights and permissions. Published by BMJ.

For numbered affiliations see end of article.

Correspondence to Dr Jee-Fu Huang;

jfliver@kmu.edu.tw

\section{ABSTRACT}

Objectives Hepatitis C virus (HCV) infection is the leading cause of cirrhosis and hepatocellular carcinoma worldwide. Tzukuan, located in the southwestern area of Taiwan, is an HCV hyperendemic area ( $>30 \%)$. This study aimed to assess the changing epidemiological characteristics of HCV infection and to evaluate the longterm outcomes after the implementation of public health strategies for two decades.

Design A population-based retrospective cohort study. Setting A comprehensive care programme was implemented, namely COMPACT Study, in Tzukuan since 1997.

Participants A total of 10714 residents participated the screening.

Outcome measures The HCV status, demographic and clinical profiles of the participants were recorded and validated annually from 2000 through 2019.

Results The HCV infection prevalence rates were $21.1 \%(1076 / 5099)$ in $2000-2004,18.8 \%(239 / 1269)$ in 2005-2009, 14.1\% (292/2071) in 2010-2014 and 10.3\% (234/2275) in 2015-2019 ( $p$ for trend test $<0.0001$ ). Among them, 1614 underwent repeated tests during the follow-up period. The annual incidence rates were $0.54 \%$ in $2005-2009,0.4 \%$ in $2010-2014$ and $0.22 \%$ in 2015-2019, respectively ( $p=0.01)$. In addition to old age, lower education level was a major risk factor for HCV infection across different periods. HCV infection prevalence rate among those illiterates reached $40.9 \%$, followed by $28.5 \%$ in those with elementary school level, and $<10 \%$ in those with high school or higher levels. The major risk factor has shifted from iatrogenic exposure in 2000-2009 to household transmission after 2010.

Conclusions HCV infection has been decreasing and the epidemiological features are changing in the hyperendemic area by continuing education, prevention and treatment strategies.

\section{INTRODUCTION}

Hepatitis $\mathrm{C}$ virus (HCV) infection is the leading cause of chronic hepatitis $\mathrm{C}$, liver
Strengths and limitations of this study

- The major strength of the study was to investigate the changing prevalence and incidence of a hepatitis $\mathrm{C}$ virus (HCV) hyperendemic area in the longest follow-up period.

- This was the first to assess whether a comprehensive and continuous public health programme is effective in decreasing the HCV hyperendemic in a community setting.

- The changes of epidemiological features deserved elucidation in a long follow-up period.

- The community effectiveness of HCV treatment might be periodically assessed with the recent tremendous progress in HCV treatment regimens.

- The application of the current model in different regions awaits further evaluation

cirrhosis and hepatocellular carcinoma (HCG) worldwide. ${ }^{12}$ Taiwan is not an exception for HCV infection with a general prevalence rate of 3.3\%. ${ }^{34}$ Approximately 745109 patients had HCV infection, and only $8.1 \%$ of these HCV patients have received successful antiviral therapy. ${ }^{3}$ Of note, there were scattered hyperendemic areas in the southwestern coast with a high prevalence rate reaching $40 \%$. Therefore, there is a pressing need to ameliorate and/or eliminate the hyperendemic situation in order to achieve the goals of HCV elimination proposed by WHO by 2030. The effectiveness validation of interventional strategies could pave the way for future implementation of public health strategies in other HCV hyperendemic areas in Taiwan and other countries worldwide.

Tzukuan, located in the suburban area of Kaohsiung City in southern Taiwan, was one of the HCV hyperendemic areas in Taiwan. 
It had an extremely high anti-HCV+ prevalence $(>40 \%)$ among adult residents with an annual incidence rate of $4.5 \% .^{5}$ Moreover, $90 \%$ of patients with HCC in this town were attributed to have HCV infection. ${ }^{5}$ Against this background, several preventive measures of community health have been vigorously implemented in the past two decades. A specific study was conducted for Tzukuan: a comprehensive healthcare system targeting hepatitis C virus infection in an endemic area of Taiwan (COMPACT) since 1997. The efforts included mass screening among residents, public education and advocacy, group education programmes for healthcare workers, referral for antiviral treatment and provision of risk-reduction counselling. ${ }^{6-8}$ The significant amelioration of the anti-HCV epidemic in both adults and teenagers proved the efficacy of public health strategies implemented for one decade ${ }^{6-8}$ With the tremendous changing landscape of HCV management in terms of diagnosis and treatment, there is a need to elucidate the long-term follow-up characteristics in a public health setting.

Consequently, the present study was conducted to assess the changing prevalence and incidence of HCV infection in Tzukuan in the past decades. In addition, this study also aimed to evaluate the changing status of the major hurdle of HCV elimination, mainly disease awareness, in the hyperendemic areas.

\section{METHODS}

\section{Design}

This population-based retrospective cohort study was conducted in subjects living in Tzukuan Township. The study was conducted after obtaining approval from the ethical committee of Kaohsiung Medical University Hospital and according to the Declaration of Helsinki. All patients provided written informed consent before study entry.

\section{Setting}

Tzukuan Township, with an area of $11592 \mathrm{~km}^{2}$, is located in the northern suburban area of Kaohsiung City in southern Taiwan. The total population was 40 444, 37000 and 35843 in 1997, 2005 and 2019, respectively. ${ }^{9}$ Since 1997, a programme has been implemented: a comprehensive care programme, namely COMPACT Study. The programme included several screening stations providing a free liver disease survey for residents. Their results were monitored annually by Kaohsiung Medical University Hospital. The effectiveness and follow-up assessments were performed in related institutions such as schools, administration bureau, community centres, clinics and medical referral centres.

\section{Data collection}

The flowchart of residents enrolled for further analysis is shown in figure 1. Liver disease screening tests, which included measuring for HBsAg, anti-HCV, aspartate and alanine aminotransferases (AST and ALT, respectively)

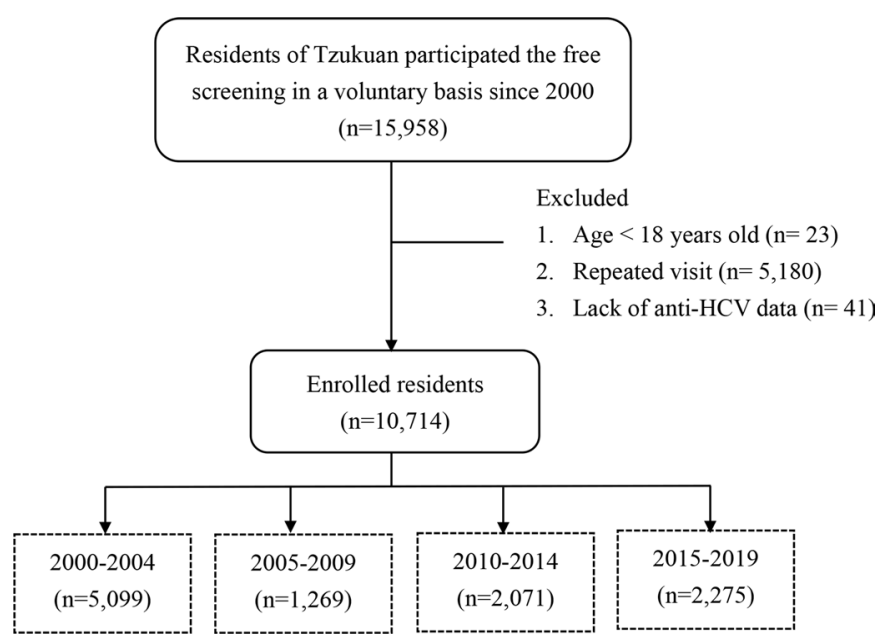

Figure 1 Flow chart of the study.

levels, were performed in all residents of Tzukuan. All the demographic data and examination data were consecutively collected in follow-up database. Those who were not residents of the area were excluded.

\section{Laboratory examinations}

Serum AST and ALT levels were measured using an autoanalyser (Hitachi, Tokyo, Japan). Anti-HCV tests were performed using a second-generation or thirdgeneration commercially available ELISA kit (AxSYM 3.0; Abbott Laboratories, North Chicago, IL, USA). All reactive samples were tested in triplicate and confirmed by HCV RNA assay. Detection of serum HCV RNA was performed using a standardised, automated qualitative reverse transcription PCR assay (COBAS AMPLICOR Hepatitis C Virus Test, V.2.0; Roche, Branchburg, NJ, USA). All tests were performed in duplicate. The detection limit was $50 \mathrm{IU} / \mathrm{mL}$. Further, a self-administered structured questionnaire, including questions on blood transmission (blood transfusion, surgery, medical injections, dental procedures, acupuncture, tattoo and body piercing), medical history and family medical history, was designed to identify possible routes of infection.

\section{Statistical analysis}

Continuous variables were expressed as mean $\pm \mathrm{SD}$, and the differences between groups were evaluated using Student's t-test (or ANOVA). The overall and age-specific $\mathrm{HCV}$ prevalence and annual incidence rates across the four periods (2000-2004, 2005-2009, 2010-2014, 20152019) were calculated using Pearson $\chi^{2}$ test (or Fisher's exact test when $\mathrm{n}<5$ ). The Cochran-Armitage test was used to evaluate the trend of prevalence. In univariate and multivariate logistic regression, the risk factors for HCV infection were expressed by ORs and their 95\% CIs. All statistical analyses were performed using JMP V.14.0 (SAS Institute, Cary, NC, USA), and $p$ value $<0.01$ with the two-tailed test was considered to indicate statistical significance. 


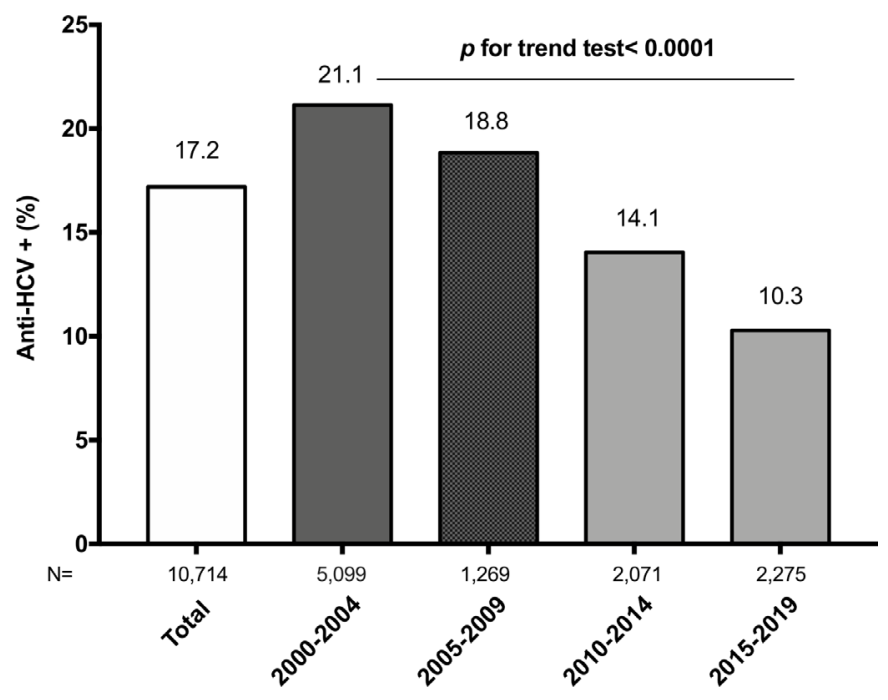

Figure 2 Changing hepatitis $\mathrm{C}$ virus (HCV) prevalence across different time periods in Tzukuan.
Patient and public involvement statement

This research was done without patient involvement. Patients were not invited to comment on the study design and were not consulted to develop patient relevant outcomes or interpret the results. Patients were not invited to contribute to the writing or editing of this document for readability or accuracy.

\section{RESULTS}

Subject characteristics and prevalence trends

Among 10714 residents who underwent initial examination, 5099, 1269, 2071 and 2275 residents visited during the periods of 2000-2004, 2005-2009, 2010-2014 and 2015-2019, respectively (figure 2). Their mean age was $39.6 \pm 18.4$ years, and $5867(54.8 \%)$ residents were women (table 1). There were $1842(17.2 \%)$ residents with anti-HCV seropositivity. Among 46 subjects who have received antiviral treatment, IFN-based regimens,

\begin{tabular}{|c|c|c|c|c|c|}
\hline Variables & Subjects & Total $(n=10714)$ & Anti-HCV- (8872) & Anti-HCV+ (1842) & $P$ value \\
\hline Age (years) & 10705 & $39.6 \pm 18.4$ & $36.5 \pm 17.5$ & $54.9 \pm 14.8$ & $<0.0001$ \\
\hline Female & 10714 & $5867(54.8)$ & $4858(54.8)$ & $1009(54.8)$ & 0.987 \\
\hline \multicolumn{6}{|l|}{ Education } \\
\hline Illiteracy & 3781 & $435(11.5)$ & $257(8.0)$ & $178(32.3)$ & $<0.0001$ \\
\hline Elementary school & & $688(18.2)$ & 495 (15.3) & $193(35.0)$ & \\
\hline High school & & $1937(51.2)$ & $1780(55.1)$ & $157(28.4)$ & \\
\hline College and above & & $721(19.1)$ & $697(21.6)$ & $24(4.4)$ & \\
\hline \multicolumn{6}{|l|}{ Risks } \\
\hline Injections or medical procedures & 4488 & $1812(40.4)$ & $1479(38.8)$ & $333(49.6)$ & $<0.0001$ \\
\hline Surgery & 4194 & $1673(39.9)$ & $1335(37.1)$ & $338(57.1)$ & $<0.0001$ \\
\hline Blood transfusions & 3996 & $258(6.5)$ & $185(5.5)$ & $73(12.2)$ & $<0.0001$ \\
\hline Persons who inject drugs & 2450 & $11(0.5)$ & $4(0.2)$ & $7(1.8)$ & 0.0004 \\
\hline Other parenteral routes ${ }^{\star}$ & 4471 & $1378(30.8)$ & $1139(30.0)$ & $239(35.6)$ & 0.0004 \\
\hline \multicolumn{6}{|l|}{ Medical history } \\
\hline $\mathrm{HBsAg}+$ & 3871 & $227(5.9)$ & $165(5.2)$ & $62(8.9)$ & 0.0001 \\
\hline Hypertension & 4108 & $618(15.0)$ & $460(13.0)$ & $158(27.4)$ & $<0.0001$ \\
\hline Diabetes & 4105 & $254(6.2)$ & $189(5.4)$ & $65(11.3)$ & $<0.0001$ \\
\hline Dyslipidaemia & 3630 & $406(11.2)$ & $349(11.0)$ & $57(12.7)$ & 0.287 \\
\hline Heart disease & 3982 & $158(4.0)$ & $110(3.2)$ & $48(8.7)$ & $<0.0001$ \\
\hline Stroke & 4085 & $61(1.5)$ & $38(1.1)$ & $23(4.0)$ & $<0.0001$ \\
\hline Renal disease & 3928 & $59(1.5)$ & $42(1.2)$ & $17(3.2)$ & 0.0005 \\
\hline Cancers & 4901 & $71(1.5)$ & $46(1.1)$ & $25(3.5)$ & $<0.0001$ \\
\hline \multicolumn{6}{|l|}{ Family history } \\
\hline Hepatitis B & 3883 & $311(8.0)$ & $282(8.4)$ & $29(5.4)$ & 0.014 \\
\hline Hepatitis C & 3884 & $257(6.6)$ & $205(6.1)$ & $52(9.6)$ & 0.0003 \\
\hline Cirrhosis & 3933 & 124 (3.2) & $100(3.0)$ & $24(4.4)$ & 0.075 \\
\hline Hepatocellular carcinoma & 3944 & $194(4.9)$ & $153(4.5)$ & $41(7.5)$ & 0.003 \\
\hline
\end{tabular}

Mean \pm SD or $n(\%)$.

*Other parenteral routes included acupuncture, tattooing and body piercing. 


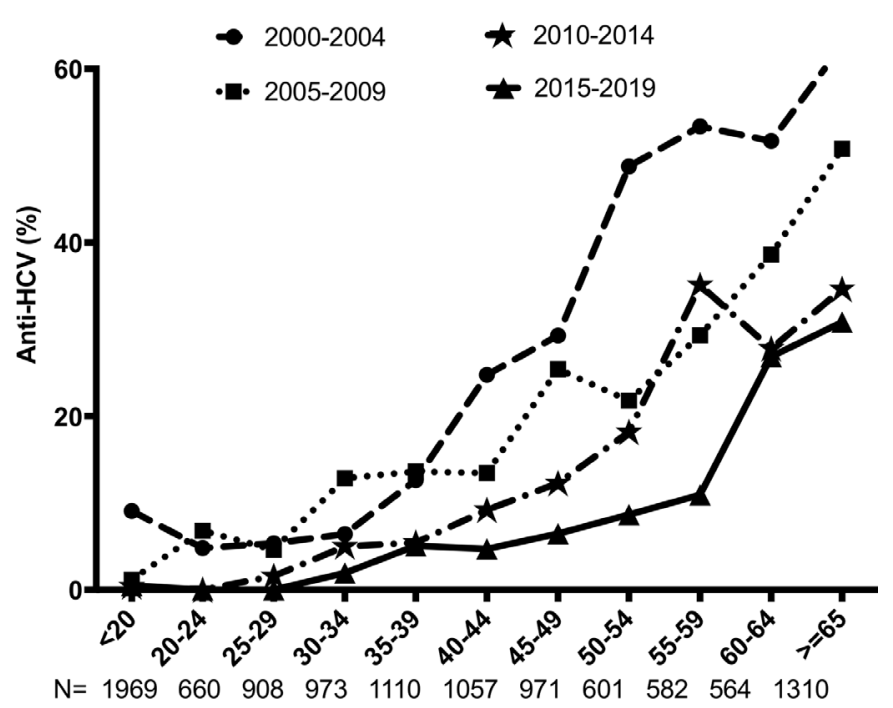

Age (years)

Figure 3 Age-specific hepatitis C virus (HCV) prevalence across different time periods in Tzukuan.

IFN-free DAAs and unknown regimens were prescribed in 27, 7 and 12 patients, respectively. The prevalence rates of anti-HCV+ were $21.1 \%$ in $2000-2004,18.8 \%$ in $2005-$ $2009,14.1 \%$ in $2010-2014$ and $10.3 \%$ in $2015-2019$ ( $p$ for trend test $<0.0001$ ) (figure 2). A significantly decreasing trend of age-specific prevalence was observed according to different time periods (figure 3). Unlicensed injections or medical procedures $(40.4 \%)$ were the major risk factors among the screened subjects, followed by surgery $(39.9 \%)$ and other parenteral routes $(30.8 \%)$ such as acupuncture, tattooing and body piercing. Blood transfusions $(6.5 \%)$ and persons who inject drugs $(0.5 \%)$ were the minor risk factors in Tzukuan.

\section{Changing features of annual incidence}

Among these 8872 anti-HCV seronegative residents, 1614 subjects underwent more than one examination during the follow-up period of 20 years. There were 37 subjects who newly developed anti-HCV+. Among them, 12, 14 and 11 subjects developed anti-HCV+ in 2005-2009, 2010-2014 and in 2015-2019, respectively. The calculated annual incidence rates were $0.54 \%$ in $2005-2009$, $0.4 \%$ in $2010-2014$ and $0.22 \%$ in $2015-2019$, respectively $(\mathrm{p}=0.01)$.

\section{Changing risk factors for HCV infection}

Table 2 shows the possible risk factors for HCV infection calculated using univariate and multivariate analyses at different time periods. In the early time period (20052009), the factors old age, lower education level, surgery and parenteral routes including acupuncture, tattooing and body piercing were significantly associated with a higher risk of HCV infection (all $\mathrm{p}<0.01$ ). In the recent time period after 2010, other risk factors such as hypertension, diabetes, heart disease, stroke and family HCV history were significantly associated with a higher risk for HCV infection (all $\mathrm{p}<0.01$ ).
Further analysis showed that HCV prevalence rate among those illiterates reached $40.9 \%$, which was significantly higher than that of $28.5 \%$ in those with elementary school level, and $<10 \%$ in those with high school or higher levels (OR (95\% CI) 1.8 (1.4 to 2.3) for elementary school level; 7.9 (6.1 to 10.1) for high school level; 20.1 (12.8 to 31.5) for college and higher levels) (figure 4). There was a 3.7-fold higher HCV prevalence in subjects whose family members had HCV infection than in those whose families do not have any HCV infection. The subjects had a higher risk of $\mathrm{HCV}$ infection contributed by their family members, ranging from 1.8-fold (1.1 to 2.9) from their mothers ( $\mathrm{p}=0.012$ ), 3.4-fold from their siblings (1.9 to 6.3, $\mathrm{p}<0.0001$ ), to 4.0 -fold from their children (1.6 to 10.5, $\mathrm{p}=0.004)$ (figure 5).

\section{DISCUSSION}

The current study provides the changing epidemiological features of the longest follow-up period in an HCV hyperendemic area where the initial prevalence was over $30 \%$. With the continuous and vigorous efforts implemented by the public and the academia, it was demonstrated that both the HCV prevalence and the annual incidence rates significantly decreased with time from 2005 to 2019 in Tzukuan township. It was observed that education level played a significant role in HCV transmission. In addition to older age, parenteral routes and family members with HCV infection were major risk factors associated with HCV infection. Thus, the study provides the exhilarating results for the implementation of public health strategies and the continuous efforts of the public. The results inspire the vigorous staff of public health and also point to the goal of eliminating HCV infection in the future.

Continuing education, prevention and treatment strategies based on the COMPACT Study have been launched in Tzukuan since 1997 according to the guidance of HCV prevention policies suggested by WHO. The policies included the following: (1) providing free screening for liver disease; (2) implementing infection control practices in healthcare settings; (3) promoting behavioural changes among the public and healthcare workers to reduce injection use and increase safe injection practices; (4) providing counselling for risk reduction and for treatment referral. The four policies of the study were the major pillars for the construction of linkage to care in a community-based setting because disease awareness and medical accessibility were the main hurdles for HCV elimination. Furthermore, free liver disease screening and promoting behavioural changes such as community education and healthcare professional education were the main educational works for raising disease awareness in this project. These results and follow-up assessments of the strategies were monitored annually by the regional university hospital, administration bureau and community care centres. ${ }^{8}$ The current study demonstrated that the amelioration of HCV hyperendemic situation could be effectively achieved by comprehensive measurements 
Table 2 Risk factors for hepatitis C virus ( $\mathrm{HCV}$ ) prevalence in different time periods

\begin{tabular}{|c|c|c|c|c|c|c|}
\hline & \multirow{3}{*}{$\begin{array}{l}\begin{array}{l}2005-2009 \\
(\mathrm{n}=1269)\end{array} \\
\text { Anti-HCV (+) } \\
\text { OR }(95 \% \mathrm{Cl})\end{array}$} & \multirow[b]{3}{*}{$P$ value } & \multirow{3}{*}{$\begin{array}{l}2010-2014(\mathrm{n}=2071) \\
\text { Anti-HCV (+) } \\
\text { OR }(95 \% \mathrm{Cl})\end{array}$} & \multirow[b]{3}{*}{$P$ value } & \multirow{3}{*}{$\begin{array}{l}2015-2019(n=2275) \\
\text { Anti-HCV (+) } \\
\text { OR }(95 \% \mathrm{Cl})\end{array}$} & \multirow{3}{*}{ P value } \\
\hline & & & & & & \\
\hline & & & & & & \\
\hline \multicolumn{7}{|l|}{ Individual risk factors } \\
\hline Age per 5-year increment & $1.4(1.3$ to 1.5$)$ & $<0.0001$ & $1.4(1.4$ to 1.5$)$ & $<0.0001$ & 1.5 (1.4 to 1.6$)$ & $<0.0001$ \\
\hline \multicolumn{7}{|l|}{ Education } \\
\hline High school vs Illiteracy & 0.1 (0.1 to 0.2$)$ & $<0.0001$ & 0.4 (0.2 to 0.6$)$ & $<0.0001$ & 0.1 (0.1 to 0.1$)$ & $<0.0001$ \\
\hline College vs Illiteracy & 0.03 (0.01 to 0.08$)$ & $<0.0001$ & 0.04 (0.01 to 0.10$)$ & $<0.0001$ & 0.08 (0.04 to 0.14$)$ & $<0.0001$ \\
\hline \multicolumn{7}{|l|}{ Sex } \\
\hline \multicolumn{7}{|l|}{ Blood transfusions } \\
\hline Yes vs no & 1.6 (0.9 to 2.8$)$ & 0.101 & 1.8 (1.0 to 2.9$)$ & 0.037 & 3.3 (2.1 to 5.0$)$ & $<0.0001$ \\
\hline \multicolumn{7}{|l|}{$\begin{array}{l}\text { Injections or medical } \\
\text { procedures }\end{array}$} \\
\hline Yes vs no & 1.2 (0.9 to 1.6$)$ & 0.241 & 1.0 (0.7 to 1.4$)$ & 0.927 & 2.7 (2.1 to 3.6$)$ & $<0.0001$ \\
\hline \multicolumn{7}{|l|}{ Other parenteral routes } \\
\hline Yes vs no & 1.8 (1.3 to 2.5$)$ & 0.0005 & 0.8 (0.6 to 1.1$)$ & 0.218 & 1.7 (1.3 to 2.3 ) & 0.0001 \\
\hline \multicolumn{7}{|l|}{ Medical history } \\
\hline \multicolumn{7}{|l|}{$\mathrm{HBsAg}+$} \\
\hline Yes vs no & $1.2(0.5$ to 2.5$)$ & 0.715 & 3.1 (1.9 to 4.9$)$ & $<0.0001$ & 2.1 (1.3 to 3.3 ) & 0.002 \\
\hline \multicolumn{7}{|l|}{ Heart disease } \\
\hline Yes vs no & $2.0(0.7$ to 5.2$)$ & 0.169 & $3.3(1.8$ to 5.9$)$ & 0.0001 & 3.0 (1.8 to 4.9 ) & 0.0001 \\
\hline \multicolumn{7}{|l|}{ Stroke } \\
\hline Yes vs no & $0.9(0.1$ to 3.7$)$ & 0.868 & 4.8 (2.0 to 11.6$)$ & 0.0008 & 5.0 (2.3 to 10.3$)$ & 0.0002 \\
\hline \multicolumn{7}{|l|}{ Renal disease } \\
\hline Yes vs no & 3.6 (0.7 to 19.9$)$ & 0.131 & 2.6 (1.0 to 6.3 ) & 0.056 & 2.5 (1.0 to 5.5$)$ & 0.055 \\
\hline \multicolumn{7}{|l|}{ Cancers } \\
\hline Yes vs no & 17.9 (5.9 to 54.5$)$ & $<0.0001$ & 1.2 (0.4 to 3.6$)$ & 0.740 & 2.1 (0.9 to 5.2 ) & 0.106 \\
\hline \multicolumn{7}{|l|}{ Family history } \\
\hline Hepatitis B & & & & & & \\
\hline Yes vs no & NA & NA & $1.0(0.5$ to 1.8$)$ & 0.995 & $0.6(0.3$ to 1.0$)$ & 0.041 \\
\hline Hepatitis C & & & & & & \\
\hline Yes vs no & NA & NA & 2.0 (1.2 to 3.4$)$ & 0.013 & 1.9 (1.3 to 2.9$)$ & 0.003 \\
\hline Cirrhosis & & & & & & \\
\hline Yes vs no & NA & NA & 2.1 (1.1 to 4.0$)$ & 0.026 & 1.3 (0.6 to 2.5$)$ & 0.405 \\
\hline Hepatocellular carcinoma & & & & & & \\
\hline Yes vs no & $1.1(0.2-3.8)$ & 0.908 & $2.0(1.2-3.4)$ & 0.012 & $1.7(1.0-2.8)$ & 0.065 \\
\hline
\end{tabular}




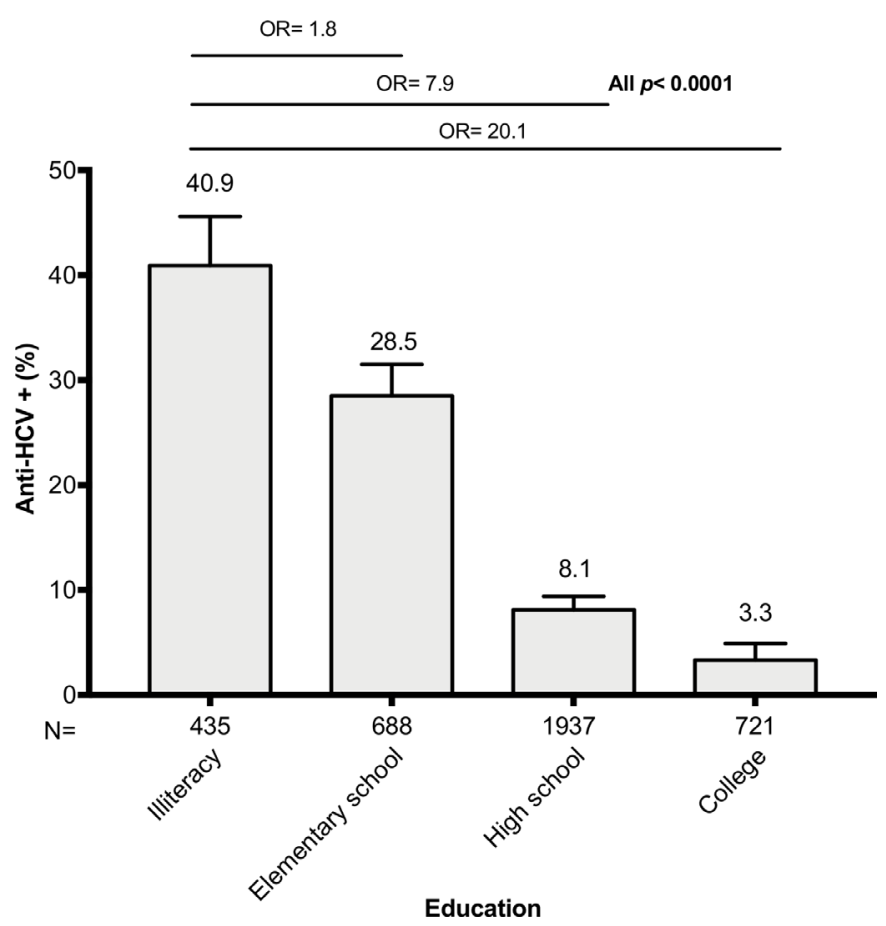

Figure 4 Hepatitis $\mathrm{C}$ virus (HCV) prevalence according to education levels.

of public health in a long-term fashion. The results were further validated by the significant decreasing trend of age-specific prevalence correlated with different time periods. The results echoed previous studies on young individuals in this township. The studies indicated that the prevalence rate in teenagers was much lower than that in adults and has significantly decreased. From 1995 to 2005, in teenagers, the prevalence of anti-HCV (2.8\% vs $1.0 \%)$ and HCV RNA $(2.3 \%$ vs $0.5 \%)$ significantly decreased in Tzukuan. ${ }^{8}$ Recently, direct antiviral agents (DAAs) have tremendously changed the treatment landscape globally and are currently the mainstream of

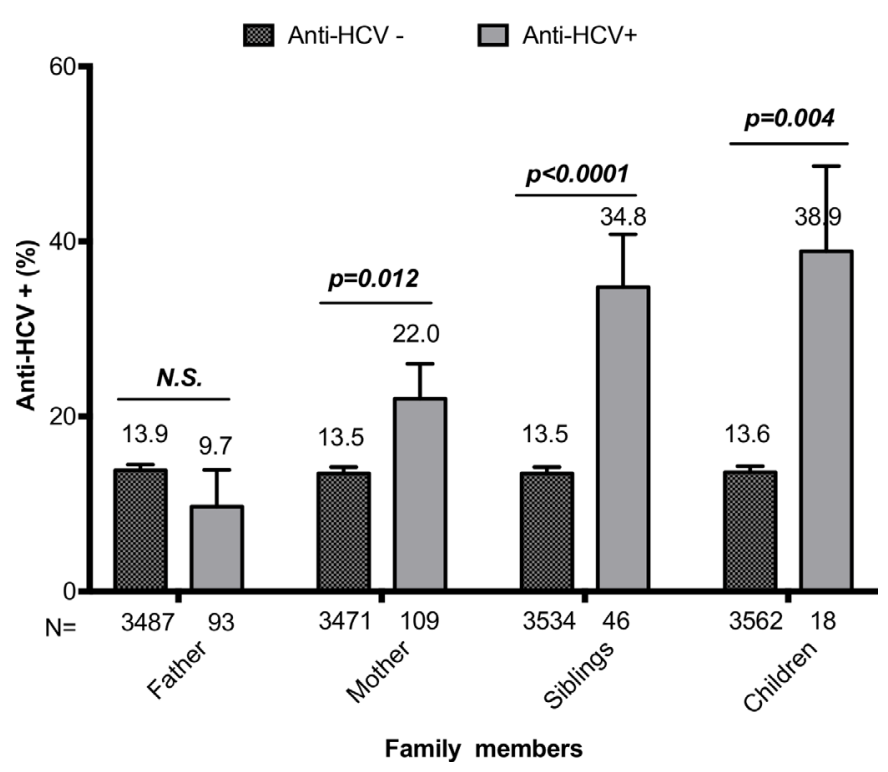

Figure 5 Hepatitis $\mathrm{C}$ virus (HCV) prevalence according to anti-HCV+ family members.
HCV treatment currently. It follows that the significant decreasing time-dependent trend will be anticipated in the new era of HCV treatment. Whether the accelerating speed of HCV elimination did exist awaits elucidation.

WHO indicated that HCV is one of the major public health threats, and its elimination is a must by 2030 . Decreasing the prevalence in highly endemic areas is the main pathway towards microelimination. Incidence of new HCV infection in the high endemic area is also essential for disease control. The incidence of HCV infection among adults in Tzukuan decreased from $4.5 \%$ to $0.74 \%$ from 1997 to $2005 .{ }^{56}$ The current study further extended the observation period, showing that the annual incidence among adults significantly decreased from $0.54 \%$ in $2005-2009,0.4 \%$ in $2010-2014$ to $0.22 \%$ in $2015-2019$. Nonetheless, the anti-HCV+ prevalence among those aged $\geq 65$ years remained high. Generally, HCV infection is an acquired infectious disease, and the prevalence of HCV infection thus increases with age. Multiple comorbidities and the disease awareness might be the hurdles for the successful eradication in the elderly population. The effectiveness of HCV management in elderly individuals could be a challenging task in a community setting.

Risk stratification is essential for the clarification of the epidemiological features of HCV infection in hyperendemic areas. From a public health perspective, a key feature of HCV is that the different transmission routes have resulted in the spread of the disease among a wide range of population. HCV is primarily transmitted through direct percutaneous exposure to blood. Mucous membrane exposures to blood also can result in transmission, although this route is less efficient. Iatrogenic factors such as non-sterile acupuncture, dental procedures, cosmetic procedures, and sharing the needle and syringe were the major vehicles for HCV transmission in several high endemic areas reported of Taiwan. ${ }^{6}{ }^{10} \mathrm{~A}$ previous study demonstrated that the main risk factors of transfusions and anti-HCV-positive families were not significant among teenagers after one decade in Tzukuan. ${ }^{8}$ The current study represented a long-term follow-up community study showing that the risk factors have shifted to individual hypertension, diabetes, heart disease and stroke in the recent follow-up period. In addition to the rapid ageing change in Taiwan, the results may imply the effective results of prevention and treatment strategies. The strategies mainly included the initiation of health promotion programmes and the the National Health Insurance Scheme for generalised treatment, which was launched in 1995 with a coverage rate of $\geq 98 \%$ of residents in Taiwan. Meanwhile, although vertical transmission is not an important route of transmission for $\mathrm{HCV}$, the role of intrafamily transmission deserves further clarification.

The current study demonstrated that low education level was significantly associated with the risk of HCV infection. Although age contributed in large part to the association, the results demonstrated that there is an inverse relationship between education level and HCV prevalence. This 
observation was concordant with that previous study by the same group demonstrating that disease awareness was the main hurdle for HCV treatment effectiveness. ${ }^{3}$ Also, the results were concordant with the previous studies showing that the significant association existed between low education level and family income and HCV infection. ${ }^{11-14}$ In a nationwide study, more than half of patients with HCV infection were not aware that they had the disease. This raised the concern that education and/or advocacy efforts should be continuously conducted in hyperendemic areas, particularly among elderly individuals. To overcome the low education level and increase disease awareness, implementing the door-to-door screening and easy-to-access home-based treatment strategies in a community setting may be more feasible in the era of DAAs. An 'outreach HCV team' to execute a door-to-door screening and to link those infected patients to an outreach clinic has been implemented in Tzukuan since 2018. The results will be informative for future modification of the related strategies. In addition, the interaction between education level and the number of family members is an interesting direction for analysis.

This study had some limitations. With the rapid tremendous progress in HCV treatment, the community effectiveness of HCV treatment regimens may have an impact on the prevalence and incidence in different periods. DAAs have not been reimbursed until 2017 by the National Health Insurance of Taiwan, which cover more than 95\% population in this country. The nationwide reimbursement also has several limitations in the first 2 years. Therefore, the impact of treatment efficacy of DAAs on the study was quite minimal. The current study defined those who were anti-HCV+ as having HCV infection, which could overestimate the prevalence because those who received previous treatment or anti-HCV+/HCVRNA- were not excluded. In addition, the diagnosis of comorbidities was mainly based on the questionnaire response from the recruited subjects. The accurate diagnosis based on the clinical aspects, preferably for a long term, will be more informative for the elucidation of the interaction between them.

In conclusion, our study demonstrated the significant amelioration of HCV in the hyperendemic area with long-term public health efforts. Data from the long-term follow-up period indicated changing epidemiological features in this area. Thus, the inspiring results are informative to achieve the goals of HCV infection elimination by 2030. The pacing towards the goals advocated by WHO will be much faster in the era of easy-to-access and extremely high efficacy of DAAs. More aggressive strategies such as door-to-door screening and home-based on-site treatment strategies may be implemented based on the finding of the current study.

\footnotetext{
Author affiliations

${ }^{1}$ Hepatobiliary Division and Hepatitis Centre, Department of Internal Medicine, Kaohsiung Medical University Hospital, Kaohsiung, Taiwan

${ }^{2}$ Faculty of Internal Medicine,College of Medicine, Kaohsiung Medical University, Kaohsiung, Taiwan

${ }^{3}$ Graduate Institute of Clinical Medicine, Kaohsiung Medical University, Kaohsiung, Taiwan
}

${ }^{4}$ Department of Preventive Medicine, Kaohsiung Medical University Hospital, Kaohsiung, Taiwan

${ }^{5}$ Department of Internal Medicine, Kaohsiung Municipal Ta-Tung Hospital, Kaohsiung Medical University, Kaohsiung, Taiwan

${ }^{6}$ Centre for Liquid Biopsy and Cancer Research Centre, Kaohsiung Medical University, Kaohsiung, Taiwan

Acknowledgements The authors thank the secretary help from Taiwan Liver Research Foundation (TLRF).

Contributors Conception and design: J-FH, P-CT, M-LY, M-LY, C-YD, C-FH, W-LC. Acquisition of data: J-FH, C-YD, C-FH, S-CC, M-LY, C-IH, M-HH, J-FY, P-YH, P-CL, Y-HL, JTY, M-YH, Z-YL. Data analysis and interpretation: P-CT, J-FH, C-FH, C-YD, W-LC, M-LY. Manuscript drafting and critical revising: J-FH, P-CT, C-YD, M-LY, W-LC, $\mathrm{W}-\mathrm{YC}$.

Funding The study was supported by grants from Kaohsiung Medical University Hospital (KMUH105-5R04, KMUH106-6R07, S10706 and S SA10907).

Disclaimer The Taiwan Liver Research Foundation (TLRF) did not influence how the study was conducted or the approval of the manuscript.

Competing interests None declared.

Patient and public involvement Patients and/or the public were not involved in the design, or conduct, or reporting, or dissemination plans of this research.

Patient consent for publication Not required.

Ethics approval The study has been approved by Institutional Review Board, Kaohsiung Medical University Hospital (KMUHIRB-E(I)-20180280).

Provenance and peer review Not commissioned; externally peer reviewed.

Data availability statement Data are available on reasonable request. All data relevant to the study are included in the article or uploaded as online supplemental information. All data relevant to the study are included in the article. Inquiries regarding the data sets used and/or analysed during the current study can be directed to the corresponding authors.

Open access This is an open access article distributed in accordance with the Creative Commons Attribution Non Commercial (CC BY-NC 4.0) license, which permits others to distribute, remix, adapt, build upon this work non-commercially, and license their derivative works on different terms, provided the original work is properly cited, appropriate credit is given, any changes made indicated, and the use is non-commercial. See: http://creativecommons.org/licenses/by-nc/4.0/.

ORCID iD

Jee-Fu Huang http://orcid.org/0000-0002-2752-7051

\section{REFERENCES}

1 Degos F, Christidis C, Ganne-Carrie N, et al. Hepatitis C virus related cirrhosis: time to occurrence of hepatocellular carcinoma and death. Gut 2000;47:131-6.

2 Serfaty L, Aumaître $\mathrm{H}$, Chazouillères $\mathrm{O}$, et al. Determinants of outcome of compensated hepatitis $\mathrm{C}$ virus-related cirrhosis. Hepatology 1998;27:1435-40.

3 Yu M-L, Yeh M-L, Tsai P-C, et al. Huge gap between clinical efficacy and community effectiveness in the treatment of chronic hepatitis $\mathrm{C}$ : a nationwide survey in Taiwan. Medicine 2015;94:e690.

4 Chen C-H, Yang P-M, Huang G-T, et al. Estimation of seroprevalence of hepatitis $B$ virus and hepatitis $C$ virus in Taiwan from a large-scale survey of free hepatitis screening participants. J Formos Med Assoc 2007; 106:148-55.

5 Lu SN, Chue PY, Chen IL, et al. Incidence of hepatitis $C$ infection in a hepatitis $\mathrm{C}$ endemic township in southern Taiwan. Kaohsiung J Med Sci 1997;13:605-8.

6 Tsai P-S, Chang C-J, Chen K-T, et al. Acquirement and disappearance of HBsAg and anti-HCV in an aged population: a follow-up study in an endemic township. Liver Int 2011;31:971-9.

7 Yang J-F, Lin C-I, Huang J-F, et al. Viral hepatitis infections in southern Taiwan: a multicenter community-based study. Kaohsiung J Med Sci 2010;26:461-9.

8 Huang C-F, Huang J-F, Dai C-Y, et al. Changing prevalence of hepatitis $C$ virus infection among teenagers in an endemic area in Taiwan. Trans R Soc Trop Med Hyg 2008;102:929-34.

9 Huang JF, Lu SN, Chue PY, et al. Hepatitis C virus infection among teenagers in an endemic township in Taiwan: epidemiological and clinical follow-up studies. Epidemiol Infect 2001;127:485-92. 
10 Wang CS, Chang TT, Chou P. Differences in risk factors for being either a hepatitis $\mathrm{B}$ carrier or anti-hepatitis $\mathrm{C}+$ in a hepatoma-hyperendemic area in rural Taiwan. $J$ Clin Epidemiol 1998;51:733-8.

11 Lu SN, Chen HC, Tang CM, et al. Prevalence and manifestations of hepatitis $C$ seropositivity in children in an endemic area. Pediatr Infect Dis J 1998;17:142-5.

12 Meffre C, Le Strat Y, Delarocque-Astagneau E, et al. Prevalence of hepatitis B and hepatitis C virus infections in France in 2004: social factors are important predictors after adjusting for known risk factors. J Med Virol 2010;82:546-55.

13 Denniston MM, Jiles RB, Drobeniuc J, et al. Chronic hepatitis $C$ virus infection in the United States, National Health and Nutrition Examination Survey 2003 to 2010. Ann Intern Med 2014;160:293-300.

14 Stroffolini T, Sagnelli E, Sagnelli C, et al. The association between education level and chronic liver disease of any etiology. Eur $J$ Intern Med 2020;75:55-9. 